\title{
ESTUDO DO DESEMPENHO DO REATOR DE LEITO MÓVEL COM BIOFILME (MBBR) NA REMOÇÃO DA CARGA ORGÂNICA DE EFLUENTE HOSPITALAR
}

\author{
A. M. SOARES ${ }^{1}$, B. V. da ROSA ${ }^{2}$, F. L. CARVALHO ${ }^{2}$, D. D. da SILVEIRA ${ }^{3}$, J. Z. \\ $\mathrm{NICOLODI}^{2}$ \\ ${ }^{1}$ Universidade Federal de Santa Maria, Aluna do Programa de Pós-Graduação em Engenharia \\ de Processos. \\ ${ }^{2}$ Universidade Federal de Santa Maria, Aluno(a) do Curso de Engenharia Química. \\ ${ }^{3}$ Universidade Federal de Santa Maria, Departamento de Engenharia Química. \\ E-mail para contato: brbvgs@hotmail.com
}

\begin{abstract}
RESUMO: O reator de leito móvel com biofilme (MBBR) consiste em um tratamento biológico onde os microrganismos crescem aderidos ao meio suporte móvel na forma de biofilme. O estudo avalia o desempenho do MBBR na remoção de carga orgânica a partir de efluentes hospitalares oriundos do Hospital Universitário de Santa Maria, utilizando suportes do tipo Kaldnes K3, na razão de enchimento de 60\%, movimentando-se livremente devido à aeração presente durante 100 dias de operação após aclimatação do reator, com vazão de entrada de $1 \mathrm{~L} / \mathrm{h}$. Os parâmetros avaliados foram Demanda Biológica de Oxigênio ao quinto dia $\left(\mathrm{DBO}_{5}\right)$ e Demanda Química de Oxigênio (DQO). A análise preliminar dos dados mostrou que a tecnologia é promissora para o tratamento de efluente hospitalar, sendo a eficiência média de remoção de $\mathrm{DBO}_{5}$ e DQO foi de 76,36\% e $69,54 \%$, respectivamente. A análise dos resultados utilizando o modelo de Monod para crescimento biológico mostrou boa aproximação por regressão linear.
\end{abstract}

\section{INTRODUÇÃO}

Até meados do século XX, as estações de tratamento de esgotos limitavam-se a um conjuntos de técnicas e processos clássicos e convencionais de lodos ativados, lagoas de estabilização e filtros biológicos percoladores. O desenvolvimento tecnológico, todavia, motivou o surgimento e a adaptação dos processos de tratamento, levando ao aparecimento de novas variantes destes processos de tratamento.

No final da década de 1980, na Noruega, surgiram o reator de leito móvel com biofilme. O histórico de desenvolvimento da tecnologia confirma a motivação pelo seu emprego, considerando que sua origem foi devida à necessidade de recuperação de $70 \%$ das estações de tratamento de esgotos de pequeno porte existentes na Noruega, que se encontravam sobrecarregadas e com limitado desempenho operacional (ØDEGAARD, 1994; RUSTEN, 1994). 
Os efluentes provenientes de hospitais são caracterizados por conter resquícios de medicamentos, elevado número de microrganismos e poluentes diversos, que se descartados sem tratamento, podem contaminar a fauna e a flora, além de trazer riscos para os moradores da região.

O processo de tratamento utilizando o reator MBBR procurou reunir as melhores características dos processos de lodos ativados incrementando às melhores características do processo com biofiltros. Ao contrário da maioria dos reatores com biofilme, o MBBR utiliza todo o volume reacional do reator para crescimento de biomassa. O reator também se caracteriza por apresentar maior facilidade operacional. Ao contrário do sistema convencional de lodo ativado, o MBBR não necessita de reciclo de lodo. Com isso, o crescimento de biomassa se dá sobre o suporte imerso no volume reacional (RUSTEN, et al., 2006).

O presente estudo avaliou a eficiência de uma unidade experimental em escala de bancada do reator MBBR na remoção de carga orgânica do efluente hospitalar em análise, usando suportes do tipo Kaldnes ${ }^{\circledR} \mathrm{K} 3$.

\section{METODOLOGIA}

No estudo realizado, para o tratamento do efluente hospitalar, utilizou-se um reator MBBR de formato retangular, feito de acrílico e com as seguintes medidas $12 \mathrm{~cm}$ de largura, $12 \mathrm{~cm}$ de comprimento e $40 \mathrm{~cm}$ de altura e está representado na Figura 1, tendo como volume útil 4,099 litros.

Figura 1 - Reator de Leito Móvel com Biofilme.

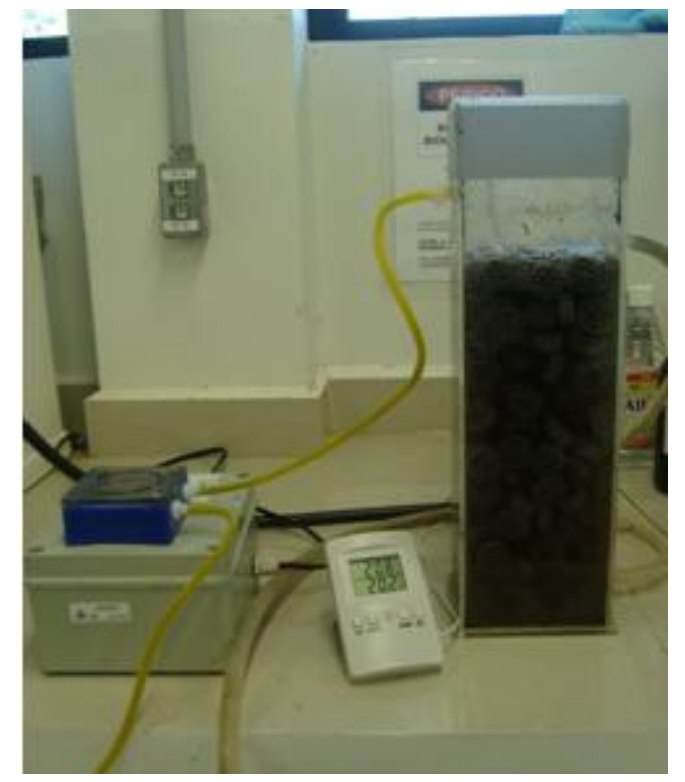

Os suportes utilizados para aderir o biofilme foram do tipo Kalness K3. Esses suportes possuem diâmetro nominal de $25 \mathrm{~mm}$, comprimento nominal de $12 \mathrm{~mm}$ e uma densidade mássica de $100 \mathrm{~kg} / \mathrm{m}^{3}$. 
Os suportes adotados melhoram o desempenho hidrodinâmico, a transferência de oxigênio e a capacidade de aplicação de altas cargas orgânicas por volume de material suporte (REIS, 2007).

A coleta de efluente no HUSM era realizada três vezes por semana, e este armazenado em um recipiente de 50 litros que era bombeado para o reator por uma bomba peristáltica da marca Provitec, Série DM 5000. A vazão de entrada do efluente era de $1 \mathrm{~L} / \mathrm{h}$, com Tempo de Detenção Hidráulica para o tratamento do efluente de $4,099 \mathrm{~h}$. A aeração do reator, responsável por fornecer oxigênio e promover a agitação ao sistema, era feita com um compressor, atuando durante 100 dias de operação após a partida do reator. A Figura 2 indica o fluxograma do processo em questão.

Figura 2 - Fluxograma de funcionamento do MBBR.

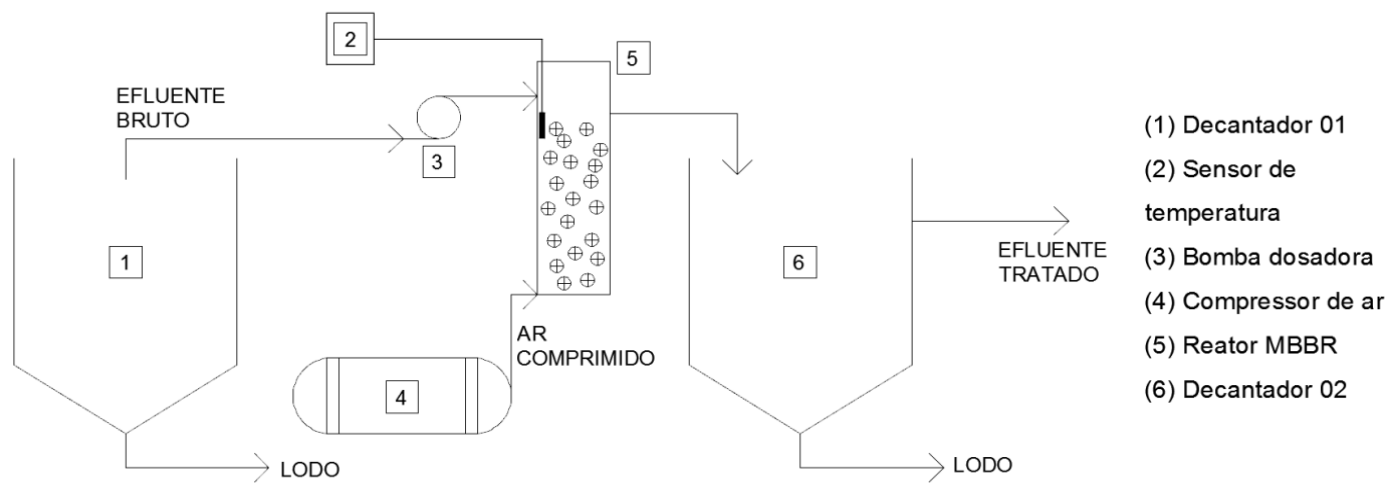

Para a aclimatação do biofilme, utilizou-se lodo gerado por outro tratamento biológico: o processo de lodo ativado de uma estação de tratamento de esgoto da própria cidade. O lodo e o efluente eram misturados em uma razão de $50 \%$ em um regime de batelada e eram alimentados diariamente no reator MBBR. Este processo de aclimatação durou 90 dias. Após, o sistema iniciou a operação contínua.

Após a entrada do reator em processo contínuo, iniciaram-se as análises, que teve como base o standard methods. O teste de DQO, utilizado para medir a quantidade de oxigênio dissolvido em meio ácido para degradar a matéria orgânica e também estimar a demanda oxidante residual de matéria orgânica no esgoto, teve como objeto de oxidação o dicromato de potássio, um forte oxidante químico.

Em muitos casos, o resultado da DQO dá uma boa estimativa de valor para a DBO, quando relacionadas. A estabilização completa, nas análises de DBO, demora, na prática, vários dias. Todavia, após 5 dias 67 a $75 \%$ da DBO é satisfeita para a maioria dos esgotos domésticos (MACEDO, 2006). Neste estudo utilizou-se um período de tempo de incubação de cinco dias, onde obtemos a $\mathrm{DBO}_{5}$. 


\section{RESULTADOS E DISCUSSÃO}

Os resultados obtidos experimentalmente nos 100 dias de operação do sistema MMBR, de $\mathrm{DBO}_{5}$ e DQO do efluente bruto, na entrada do reator MBBR, e do tratado, na saída do reator MBBR, estão apresentados nas Figuras 3 e 4.

Figura 3 - Resultados obtidos após analises de DQO feitas com o afluente e o efluente.

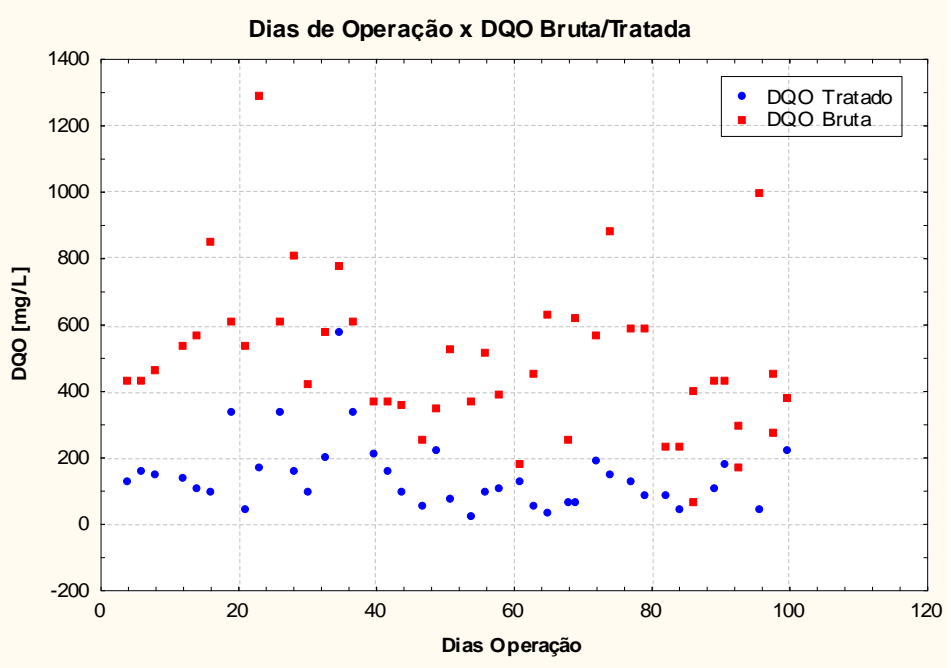

Figura 4 - Resultados obtidos após analises de $\mathrm{DBO}_{5}$ feitas com o afluente e o efluente.

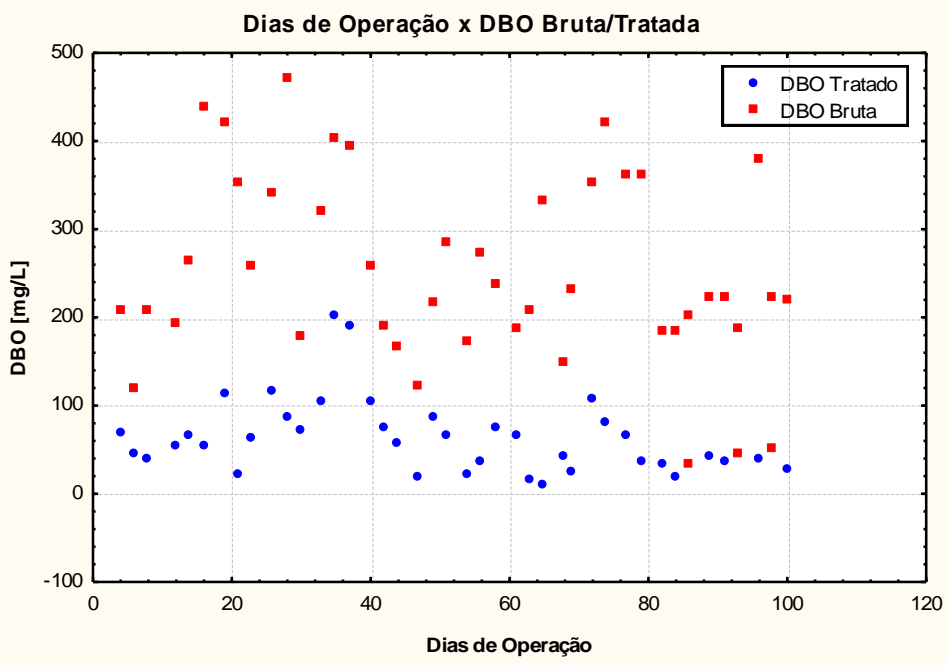

O cálculo da eficiência de remoção foi efetuado pela Equação 1,

$$
\text { Eficiência de Remoção(\%) }=100-\left[\left(\frac{C_{e f}}{C_{a f}}\right) * 100\right]
$$


onde $\mathrm{C}_{\mathrm{ef}}$ e $\mathrm{C}_{\mathrm{af}}$ são as concentrações dos parâmetros analisados do efluente e do afluentes, respectivamente.

Na tabela 01 estão apresentados os valores médios obtidos de $\mathrm{DBO}_{5}$ e DQO do efluente bruto e tratado, assim como o valor da eficiência de remoção, na fase de operação após a aclimatação do reator MBBR.

Tabela 1. Valores médios obtidos de $\mathrm{DBO}_{5}$ e DQO.

\begin{tabular}{|c|c|c|c|}
\hline Parâmetro & Média afluente $(\mathrm{mg} / \mathrm{L})$ & Média efluente $(\mathrm{mg} / \mathrm{L})$ & Rendimento $(\%)$ \\
\hline $\mathrm{DBO}_{5}$ & 264,57 & 61,83 & 76,36 \\
\hline DQO & 511,4 & 143,4 & 69,54 \\
\hline
\end{tabular}

As eficiências de remoção obtidas são comparáveis a rendimentos em outros trabalhos, tais como Andreottola et al. (2004), Pinho (2007), Oliveira (2008), entre outros.

Na sequência, efetuou-se um balanço de massa no volume de controle em análise, conforme a Equação 2 abaixo,

$$
E=S+A+R
$$

onde E e S representam a carga orgânica do efluente relativo a entrada e a saída, respectivamente, A representa o acúmulo de matéria orgânica no biofilme e $\mathrm{R}$ o conteúdo reagido.

Inicialmente, testou-se um comportamento linear, descrito na Equação 3, e, utilizandose como aproximação o modelo de crescimento biológico de Monod, obtiveram-se as Equações 4 e 5 abaixo descritas, em termos de DQO e $\mathrm{DBO}_{5}$.

$$
\begin{gathered}
y=A \cdot x+B \\
(E-S)=\mu_{\text {máx }} \cdot\left(\frac{C_{D Q O}}{k_{S} \cdot C_{D Q O}}\right)+B \\
(E-S)=\mu_{\text {máx }} \cdot\left(\frac{C_{D B O}}{k_{S} \cdot C_{D B O}}\right)+B
\end{gathered}
$$

onde $\mu_{\text {máx }}$ representa a taxa máxima específica de crescimento, $C_{D Q O}$ e $C_{D B O}$ representam as respectivas concentrações, em $\mathrm{mg} / \mathrm{L}$, de $\mathrm{DQO}$ e $\mathrm{DBO}_{5}$ do afluente e $k_{S}$ representa a constante de semissaturação.

Objetivando-se a determinação dos parâmetros $\mu_{\text {máx }}$ e $k_{S}$, a fim de propor um modelo eficaz para o crescimento biológico no reator em estudo, testou-se o modelo de regressões lineares no software STATISTICA. Inicialmente adotou-se para o valor de $k_{S}$ a média encontrada para as concentrações de entrada das duas demandas. Após o teste inicial, foram simulados novos valores para a constante $k_{S}$ até a estabilização nos valores dos parâmetros encontrados, conforme as Equações 6 e 7.

$$
K_{S}=C_{D Q O} .2 \quad(6) \quad K_{S}=C_{D B O 5} .2
$$


Com os valores de $k_{S}$ calculados, e admitindo-se para o eixo das ordenadas a diferença entre as concentrações dos parâmetros medidos de amostras das correntes de entrada e saída, e para o eixo das abscissas a razão entre a concentração dos parâmetros relativos à corrente de entrada das demandas somado o valor suposto de $k_{S}$, plotaram-se os gráficos a seguir, representados pelas Figuras 5 e 6.

Figura 5 - Modelo de Monod para DQO

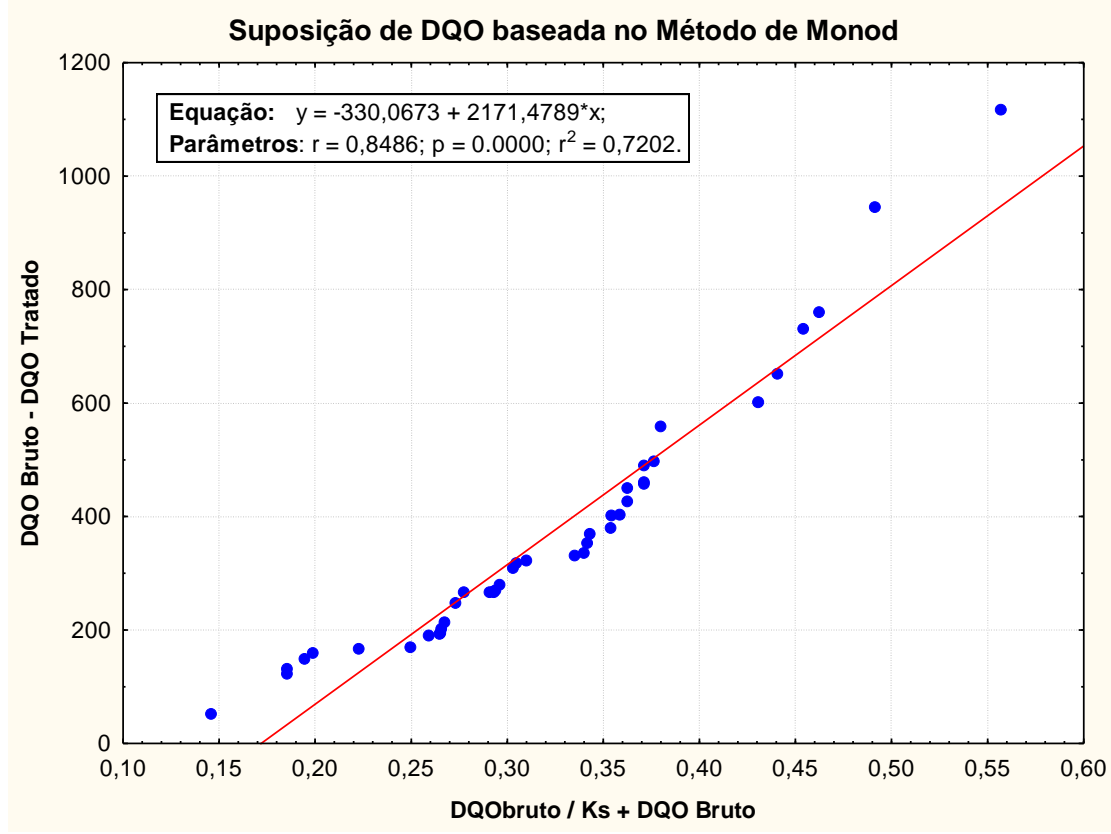

Figura 6 - Modelo de Monod para $\mathrm{DBO}_{5}$

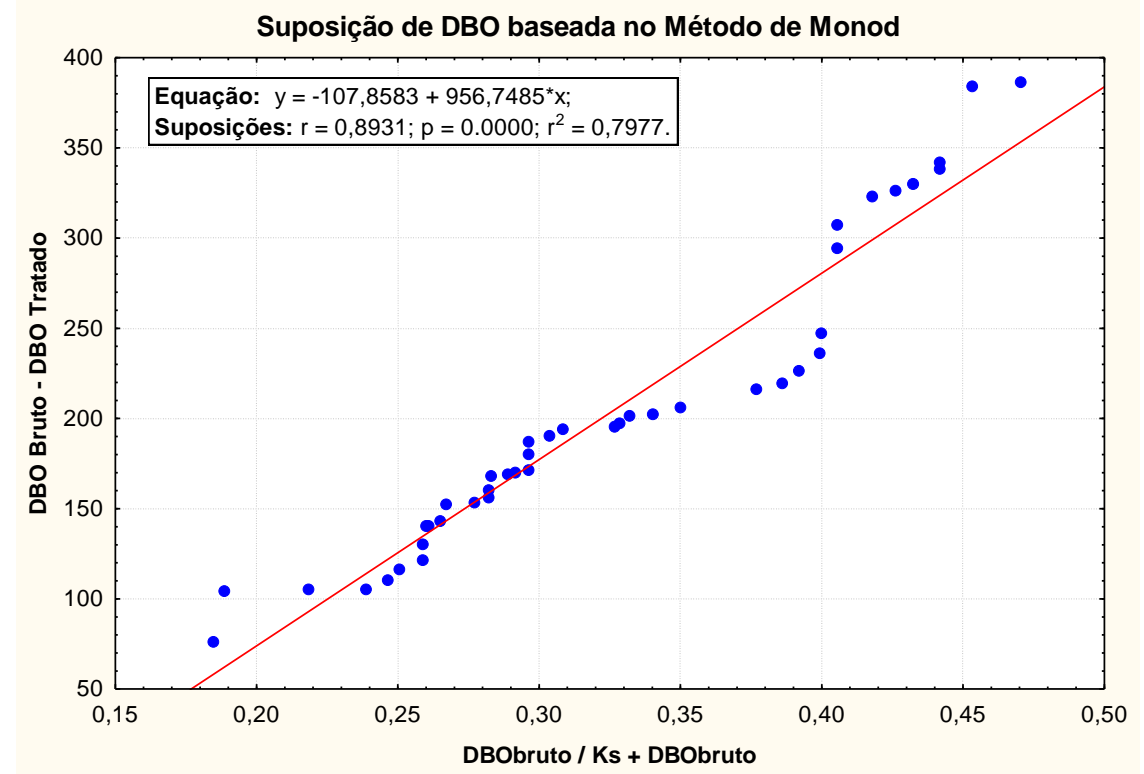


Aplicando-se o ajuste linear dos pontos, encontraram-se as Equações 8 e 9.

$$
\begin{aligned}
& y=-330,0673+2171,4789 x \\
& y=-107,8583+956,7485 x
\end{aligned}
$$

Dessa forma, tendo em vista que os valores de correlação linear, graficamente representadas pela letra " $r$ ", apresentaram valores superiores a 0,8 , observa-se que os valores obtidos nesta primeira análise foram satisfatórios. Resumidamente, obtêm-se, então, os parâmetros procurados:

$$
\begin{aligned}
k_{S_{D Q O}} & =1022,841 \\
k_{S_{D B O}} & =529,1429 \\
\mu_{\text {máx }} & =2171,4789 \\
\mu_{\text {máx }} & =956,7485
\end{aligned}
$$

Observa-se que para o modelo inicialmente testado as constantes cinéticas são elevadas, provavelmente devido à presença de compostos persistentes ou xenobióticos, as quais são normalmente encontrados em efluentes hospitalares, alguns com meia-vida superior a 2000 h (Kümmerer, 2004).

A fim de obter-se um modelo mais preciso, sugere-se à novos testes a utilização de outros modelos para o crescimento biológico.

\section{CONCLUSÃO}

O sistema de tratamento utilizando o reator MBBR mostrou-se satisfatório, no que se refere à remoção de matéria orgânica, expressa como $\mathrm{DBO}_{5}$ e DQO, já que se obtiveram eficiências médias de remoção, respectivamente, de $76,36 \%$ e $69,54 \%$, comparadas com outros processos para tratamentos de efluentes hospitalares. Além disso, a aplicação do modelo de Monod para avaliação do crescimento biológico de micro-organismos visando a consequente obtenção dos parâmetros se mostrou positiva ao revelar, graficamente, coeficientes de correlação superiores a 0,8 . Sugere-se, em trabalhos futuros, a utilização de diferentes modelos de crescimento biológico.

Uma possível aplicação para o modelo empregado é a utilização do mesmo em efluentes com características semelhantes.

\section{NOMENCLATURA}

DBO5 Demanda Bioquímica de Oxigênio

DQO Demanda Química de Oxigênio

HUSM Hospital Universitário de Santa Maria

$\boldsymbol{k}_{\boldsymbol{s}}$ Constante de semissaturação

MBBR Reator Leito Móvel com Biofilme (Moving Bed Biofilm Reactor) 
$\boldsymbol{\mu}_{\text {máx }}$ Taxa máxima especifica de crescimento

\section{REFERÊNCIAS}

ANDREOTTOLA, G.; FOLADORI, P.; RAGAZZI, M.; VILLA, R. Dairy wastewater treatment in a moving bed biofilm reactor. Water Science and Technology. v. 45, n. 12, p. 321-328, 2004.

APHA/AWWA/WEF. Standard Methods for the Examination of Water and Wastewater. 18. ed. Washington: American Public Health Association, 1998.

KÜMMERER, K. Pharmaceuticals in the Environment: sources, fate, effects and risks. $2^{\text {nd }}$ Ed., Berlin: Springer, 2004. 527p.

MACEDO, J. A., Introdução à química ambiental, Juiz de Fora, MG, CRQ-MG, 2006, $2^{\mathrm{a}}$ Ed., 1028p.

ØDEGAARD, H.; RUSTEN, B.; WESTRUM, T. A new moving bed biofilm reactor applications and results. Water Science and Technology. v. 29, n. 10-11, p. 157-165, 1994.

PINHO, M. L. F. Aplicabilidade do reactor MBBR no tratamento de efluentes vínicos. Dissertação de Mestrado. Universidade de Aveiro, PT,117p, 2007.

REIS, G. G.; Influência da Carga Orgânica no Desempenho de Reatores de Leito Móvel com Biofilme (MBBR). Dissertação de Mestrado. Universidade Federal do Rio de Janeiro, RJ, 2007.

RUSTEN, B.; EIKEBROKK, B.; ULGENES, Y. et al. Design and operations of the Kaldnes moving bed biofilm reactors. Aquacultural Enginnering, v. 34, n. 3, p. 322-331, 2006. 